\title{
How to Find New Ways
}

\author{
Simon Florian \\ University Hospital Düsseldorf, \\ Germany
}

\section{Introduction}

Subject of this article is to show how research can be build up and what fields are to consider. If you want to perform modern research you have to look at different aspects of the same problem. Therefore we established three research groups to illuminate the problem of ischemia and reperfusion injury after aortic clamping. The aim of this three study groups is to find answers to questions in the field of pre- and perioperative conditioning to improve the outcome or even avoid negative effects of an ischemia reperfusion injury upcoming every day in the clinical situation of a vascular surgeon.

There is a high prevalence of hypertonia and arteriosclerosis in the industrial countries in our days. Therefore we have to expect an increase in the incidence of aortic aneurysms and the need for surgical intervention. Other reasons for aortic damage are injuries after trauma and dissections of the vascular wall. Thoracic aneurysms appear in nearly $25 \%$ of the cases whereas abdominal aneurysms take place in round about $75 \%$. In most of the cases the aneurysm has to be resected operatively. During this procedure the blood flow is stopped by two clamps putted up- and downward of the aneurysm. The aneurysmatic vessel is replaced by prosthesis and blood flow is restored (Orend 1995). This means that all organs, supplied by this part of the aorta, are suffering from ischemia during the surgical procedure.

Nearly $30 \%$ of all patients, undergoing surgical replacement of the thoracic-abdominal part of the aorta, are suffering afterwards from severe postoperative problems. These problems are caused by the inevitable ischemia of the lower body half during the clamping and the following reperfusion injury, taking place with the declamping of the aortic vessel. This is the reason why the replacement of an aortic aneurysm is a classical clinical example of an ischemia and reperfusion sequence. The most frequently upcoming complications after elective, open surgical repair of an aortic aneurysm are cardiovascular and respiratory insufficiency. Intraoperatively patients are endangered mostly by the huge change in hemodynamic situation, because clamping of the aorta causes a fulminant increase in blood pressure. Without pharmacological intervention the ejection fraction of the heart would decrease by $40 \%$. An ongoing overload of the heart would end in dilatation of the left ventricle with hypoperfusion of the inner heart muscle, insufficiency of the mitral valve and lung edema resulting in cardiovascular arrest (Walther 2000). Blankensteijn et al state in a meta-analysis of 72 studies 4.9 to $13.6 \%$ as cardial and 3.8 to $13.5 \%$ as pulmonal complications (Blankensteijn 1998). 
Paraplegia as a consequence of spinal ischemia is the most important complication after reconstruction of the thoracic aorta. The incidence of paraplegia depends on the aneurysmatic dimension and comorbidities and ranges therefore from $0.5 \%$, in case of a small repair e.g. the aortic arch, to $40 \%$ in case of a ruptured thoracic aortic aneurysm (Svensson 1993, Money 1994, Zvara 2002). Several potential reasons for postoperative paraplegia were experimentally evaluated. Main subjects were amongst others ischemia and the resulting hypoxia plus an increase of the liquor pressure during the clamping period and the reperfusion injury after declamping (Crawford 1990, Bergner 1992, Zvara 2002). Ischemia and reperfusion cause an increase of free radicals that consume the existing buffer enzymes (Gelman 1995, Willett 2001). During hypoxia mitochondrial phosphorylation slows down with a consecutive loss of ATP that causes inhibition of the membrane pumps that are responsible for cell homeostasis. Finally dysbalance of the $\mathrm{Na}^{+} / \mathrm{K}^{+}$-milieu appears accompanied by hyperkalemia, acidosis and cell edema. At the end cells undergo programmed death, called apoptosis (Abe 1995). An additional aggravating factor is that the anterior motor neurons and the spinal cord have a high metabolic rate in combination with low hypoxic tolerance (Sakurai 1998), that make the neurons extremely sensitive to fluctuations in oxygen supply. Another important thing is the time factor, because clamping shorter than 30 minutes shows only little impact on the neurological tissue while longer ischemia periods coincide with a high risk for neurological damage like e.g. paraplegia (Hatori 2000, Wahlberg 2002, Roques 2003). Adequate blood supply for the spinal tissue can be measured electro physiologically by using somatosensoric (SEP) or motor evoked potentials (MEP). SEP's show mainly the signal transduction of the dorsal part of the spinal cord while the MEP's allow the monitoring of the neurons of the anterior horn and of the tractus corticospinalis. Experiments comparing these two methods showed that SEP's react with a delay on spinal cord ischemia and have a high wrong positive rate. In contrast 18 out of 38 patients that underwent thoracic-abdominal reconstruction of the aorta showed pathological MEP-results. This changing's in MEP measurement were attenuated by protective procedures e.g. reinsertion of segmental arteries. A loss of more than $75 \%$ of the baseline MEP amplitude was taken as a sign for an ischemic spinal cord dysfunction. Paraplegia rate in this study, using MEP monitoring, was 0 \% (de Haan 1999, Meylaerts 1999, 2000).

The risk for renal complications is about 15 to $20 \%$ and depends on location of aneurysm, mainly of the lower thoracoabdominal or infrarenal aorta (Back 2005) and on potentially existing preoperative damages of the renal tissue of the patients. Creatinine levels over 230 $\mathrm{mmol} / \mathrm{L}$ and - or renal ischemia time over 60 minutes increase the risk of postoperative necessary dialysis, that occurs in 5 to $10 \%$ of the cases (Kazautchian 1994). In patient with acute kidney failure that results in postoperative dialysis prognosis worsen dramatically with an increase of mortality up to $75 \%$. The higher the preoperative creatinine level the poorer the postoperative outcome of the patients (Svensson 1993). These facts show the need for new strategies to attenuate the harmful impact of ischemia and reperfusion on the spinal cord and the renal tissue. Before patients can benefit from new e.g. drugs and therapies that avoid tissue damage, experiments must be done, that ensure safety to humans. Therefore a valid experimental model to investigate new strategies in the field of ischemia and reperfusion is warranted. The next chapters show how our group is working on different aspects of the same problem, namely ischemia and reperfusion, to show up new strategies and hopefully give answers to questions of clinical problems in a vascular department. 


\section{Large animal model}

For the realisation of a valid large animal model pigs are the appropriate species. Anatomically (position and configuration of the thoracic and abdominal organs, spinal cord and blood supply) metabolically as well as physio- and pathophysiologically pigs show the biggest homology with humans (Dodds 1982). We used pigs of both gender with a body weight of 40 to $50 \mathrm{~kg}$ in average and about 3 to 4 month of age. Furthermore other animal models were described before by other experimental groups (de Haan 1999, Hellberg 2000, Meylaerts 1999, 2000). Therefore we adapted the experimental setup to fit our special needs to examine ischemia and reperfusion in a standardised model (Schelzig 2003, Kick 2007). Another advantage of a large animal model is the easy surgical preparation, the possibility for neurological examinations and the acquisition of enough blood samples for further analytics. Via femoral cut down, catheter sheaths were introduced into the Aa. femorales sinistra and dextra for distal blood pressure recording and placement of inflatable balloon catheters. One catheter was placed directly above the porcine aortic bifurcation, the other one directly downstream of the A. subclavia sinistra as shown in Figure 1.

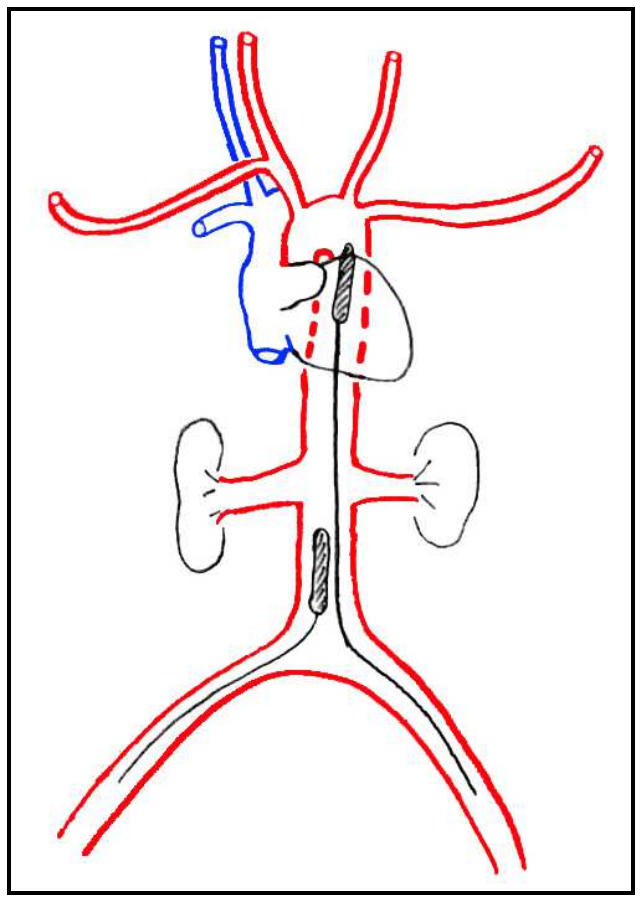

Fig. 1. Position of the two inflatable balloon catheters.

This approach was chosen in order to prevent any perfusion of the spinal cord via collateral flow distal to the proximal balloon, which could result from variable origin of the $A$. radicularis magna anterior. The intra-aortic balloon occlusion was used in order to avoid the mechanical injury, related to a clamp placement and release per se. A mini-laparotomy was performed to place a catheter into the bladder for save and controlled urine sampling. To 
examine the neurological function of the spinal cord we established motor evoked potentials (MEP) that were already described above. Three electrodes were placed in the pig's calvarium and one in the soft palate for electric stimulation of the motor cortex. Answers of the peripheral nerves were assessed in the lower limbs. After this model was well established over several years we tested different substances to see if there is any benefit compared to control groups. The next chapters give a short overview of some of the studies performed with this animal model.

\subsection{Erythropoietin (EPO)}

One of the first drugs we tested was erythropoietin (EPO). The reasons for choosing a substance that is known for so many years were the experimental results of other groups that discovered new aspects of EPO. Experiments dealing with apoptosis and neurological disability after ischemic impact on the spinal cord showed that EPO had not only some positive effects but seemed to attenuate the damage to the motor neurons at a notable range (Celik 2002). There were also reports of improved renal tissue function after ischemia and reperfusion in animal models (Ates 2005, Forman 2007). Interestingly EPO was already in focus of human studies dealing with stroke and also reporting beneficial effects in the patients outcome, even though this results were only preliminary (Ehrenreich 2002). After we were sure that EPO would be an interesting candidate to take a closer look at, we had the problem of which doses to take, because most of the experiments in literature used high EPO doses. Only some experimental groups examined doses comparable to those used in hospital dealing with anemia (Silver 2006) also showing positive effects on spinal cord and kidney damage after trauma and ischemia and reperfusion (Kaptanoglu 2004, Abdelrahman 2004). Therefore we started our large animal experiments dealing with "low dose" EPO and its effects on spinal cord and kidney function after an ischemia and reperfusion sequence.

14 anesthetized, ventilated and instrumented pigs twice received EPO (n=8; 300IU $/ \mathrm{kg}$ both over 30 minutes before as well as over 4 hours during reperfusion) or vehicle $(n=6)$. During the early reperfusion period i.v. noradrenaline was titrated continuously as required to maintain MAP $>80 \%$ of the baseline level. Kidney function was assessed by PAH- and creatinine-clearance, spinal cord function by motor evoked potentials and lower extremity reflexes, respectively. DNA damage in whole blood samples was evaluated with the alkaline version of the comet assay. Oxidative stress was determined by isoprostane, catalase and superoxiddismutase in blood and renal tissue. After 8 hours of reperfusion post mortem tissue samples were taken for histological evaluation. Kidney and spinal specimen were analysed for apoptosis (TUNEL-assay). Spinal cord damage was quantified using the Nissl staining. Results show that conditions were stable throughout the whole experiments, meaning that as well hemodynamics as parameters of gas exchange were comparable between both groups without significant differences. This is a strongly recommended requirement to gain results that allow comparison of the experimental groups. Interestingly the amount of given noradrenaline, needed to keep blood pressure in the targeted range, was significantly lower in the EPO treated group. The fact of stable hemodynamics in combination with lower need for catecholamine may indicate an improved peripheral vascular resistance. It is also possible that vasoconstrictor vessel response is improved by EPO. Because of the shortness noradrenaline must be given, it is very likely that with EPO treated animals also have an improved cardiac function. These findings fit well with 
findings in other experiments demonstrating positive effects of EPO on the heart of rats after myocardial infarction (Moon 2005). Although there were no clinical differences related to the spinal cord function, assessed by lower limbs reflexes and MEP-Amplitudes, we saw a significant higher number of intact neurons in the thoracic histological Nissl-stainings. This benefit unfortunately was lost in the lumbar histological staining, while HE-staining in both, the thoracic and the lumbar slices, showed cytoplasmatic swelling and vacuolisation as an indicator for spinal cord injury.

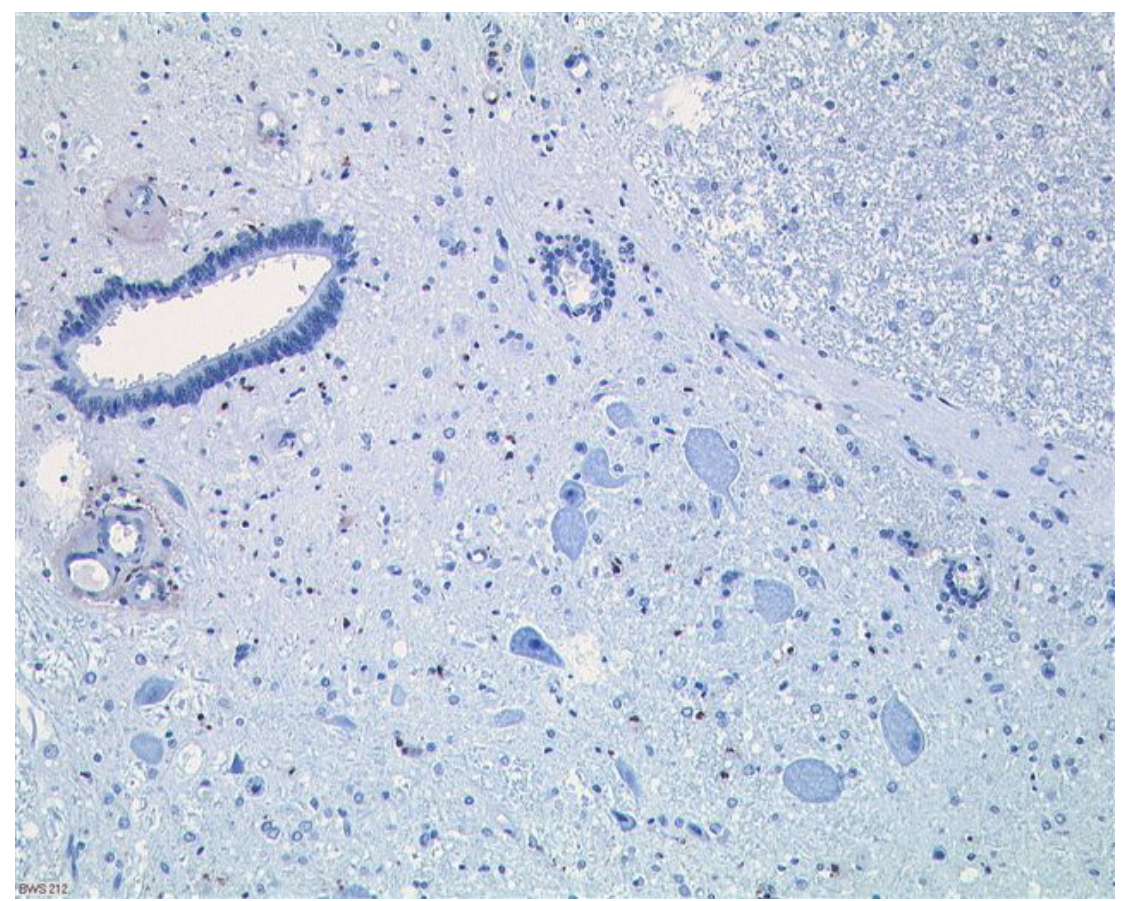

Fig. 2. Nissl-staining of a spinal cord slice showing swollen neurons as a sign of hypoxic injury.

Finally TUNEL-staining of microglia and astrocytes also imposed with less damage in the thoracic slices, but not at the lumbar level. These results show a positive effect of EPO on the neurological tissue, but this does not mean necessarily also an intact clinical outcome. One forth of the neurons was damaged by hypoxia, what might be too less for a proper function. The results of the kidney function showed an improvement as well of the creatinine clearance as of the fractional Na-excretion. Important in this context is that renal hemodynamics, namely renal blood flow, were comparable between the two groups meaning that differences between the groups are no artefacts caused by different postischemic perfusion. Urine production however was comparable between the groups. Interestingly these renal differences had no equivalent in the histological HE- or the TUNEL-staining. At least even systemic parameters of oxidative stress and antioxidant enzyme activity showed no intergroup differences. We can only have a guess why we have clinical relevant effects of EPO on the glomerular and tubular kidney function but see no 
histological or oxidative stress parameters. One point of view might be that 45 minutes of ischemia is a relatively low challenge on renal tissue so that temporarily improved global renal function must not result in histological changing's demonstrating a severe damage to the kidney tissue. This aspect is underlined by the gentle increase in plasma creatinine that indicates a possible recovering of the kidneys without any therapeutic intervention. The other point is that a reperfusion period of 8 hours might be too short to see already histological damages in renal tissue when the ischemic stress was not very excessive. In conclusion we can say that EPO has beneficial effects on cardiac and vascular hemodynamics, it improves the surviving of neuronal tissue and it protects kidney from acute failure. The lesson we learned out of that, was, that we can not examine two different organs in one single experimental setup and therefore have to split experiments in future. On the one hand we will have the spinal cord group with shorter clamping period and on the other hand we will have the kidney branch with prolonged ischemia time (Simon 2008).

\section{$2.2 \mathrm{H}_{2} \mathrm{~S}$ - proof of principle}

The second substance we focused on was the hydrogen sulfide $\left(\mathrm{H}_{2} \mathrm{~S}\right)$, because there was a remarkable study in mice. In this experiment mice were exposed to an atmosphere with 80 ppm $\mathrm{H}_{2} \mathrm{~S}$. Just by inhaling this gas atmosphere the animals fell in a "suspended animationlike" metabolic status. This is characterised by reduced metabolism, hypothermia and reduced $\mathrm{O}_{2}$ demand. The interesting fact in this context was that exposition of the animals to normal atmosphere reversed all of the mentioned effects without resulting in neurological damage (Blackstone 2005). This is of specific interest while $\mathrm{H}_{2} \mathrm{~S}$ was known as a toxic agent harmful to humans (Couch 2005, Truong 2006), but recently came to mind as a third gaseous mediator (Lowicka 2007). One explanation might be the cytochrome oxidase c inhibition and the resulting reduction of the mitochondrial respiratory chain work und thus protecting animals from getting harmed by lethal hypoxia (Khan 1990, Blackstone 2007). To get further information if a "suspended animation-like" status is clinically relevant we wanted to know if we can translate the mice experiments in our large animal model, because small animals drop their body temperature much easier than large animals or humans and this might be a very important difference. Two major hypotheses were investigated: Is it possible to induce a reduced metabolic status in our large animal model as described in mice by using $\mathrm{H}_{2} \mathrm{~S}$ as an i.v. formulation, to avoid airway irritation of the sulfide gas. Second aim was to see if $\mathrm{H}_{2} \mathrm{~S}$ has any effect on the cardiovascular system, because sulfide was reported to be protective to the post-ischemic heart function (Johansen 2006, Zhu 2007). After an initial bolus $\mathrm{H}_{2} \mathrm{~S}$ was given continuously with doses of $2 \mathrm{mg} / \mathrm{kg}$ per $\mathrm{h}$ until the end of the experiment. Control group received instead of sulfide only vehicle. After 2 hours of drug infusion the aortic blood flow was arrested for 30 minutes by using balloon catheters as described above. This occlusion time was chosen to investigate hemodynamics and metabolic changings and cardiovascular reaction without the adulteration of a huge inflammation reaction caused by the ischemia and reperfusion sequence. Reperfusion monitoring was 8 hours long with the followed killing of the animals in deep anaesthesia. The results showed that sulfide caused indeed a fall of heart rate and of cardiac output as well and came hand in hand with a reduction of noradrenaline in time and total amount, but did not affect stroke volume. Important in this context is that neither mean arterial nor venous pressure differed between 
the groups so that it is plausible that changing's of cardiac output was caused solely by the fall of heart frequency and that the vasoconstrictor response to the noradrenaline infusion was improved although in literature $\mathrm{H}_{2} \mathrm{~S}$ is described as an endogenous vasodilator (Bhatia 2005, Fiorucci 2006). Core temperature decreased in the $\mathrm{H}_{2} \mathrm{~S}$ stronger than in the control group and reached significance at the end of experiment. This loss of temperature came together with a lowered $\mathrm{O}_{2}$ uptake and $\mathrm{CO}_{2}$ production after 2 hours of reperfusion and remained until the end of experiment after 8 hours of reperfusion.

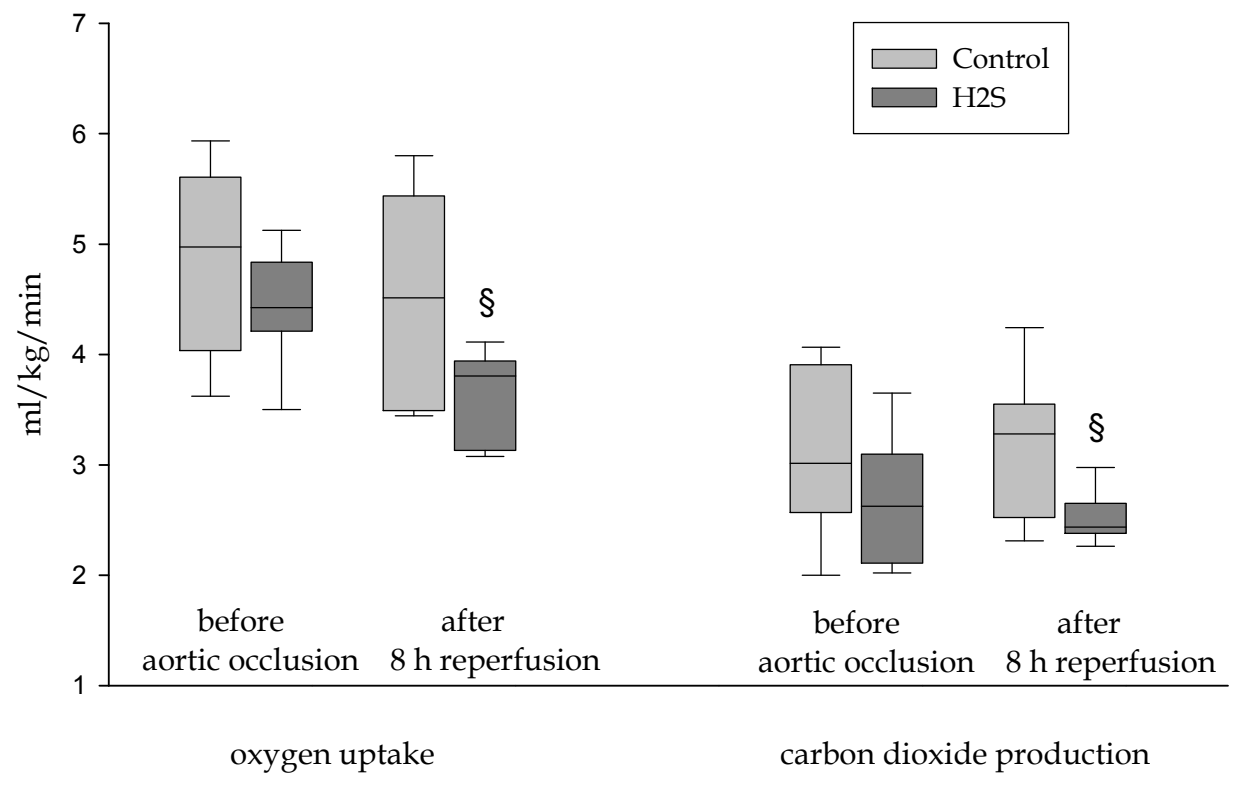

$\S$ depicts $\mathrm{p}<0.05$ control vs. sulfide.

Fig. 3. $\mathrm{O}_{2}$ uptake and $\mathrm{CO}_{2}$ production in the vehicle (light whiskers) and sulfide-treated (dark whiskers) animals. All data are median (quartiles, range), $\mathrm{n}=8$ in each group.

This reduction of metabolism also caused consequently less need for anaerobic generation of ATP and therefore also less glucose turnover. As we planed there was no intergroup difference between the parameters of inflammation and oxidative stress, namely isoprostan levels, nitrate plus nitrite and TNF-a. The reason for that mild inflammation and oxidative stress response is the relatively short ischemia, giving us the opportunity to study just the effects of sulfide per se. What we found unfortunately was a significant lower $\mathrm{pO}_{2}$ level in the sulfide group at the end of the experiments while $\mathrm{pCO}_{2}$ and acid-base status didn't change. The reason for this loss of lung function was seen when the lung was taken out at the end of the last experiment. There was a diffuse lung haemorrhage suggesting that longterm infusion of sulphide in high doses can cause pulmonary toxicity. In conclusion we demonstrated in our large animal model that i.v. $\mathrm{H}_{2} \mathrm{~S}$ reduces significantly metabolism and energy expenditure. It also reduced noradrenaline requirements during the early reperfusion period and might have positive effects on the cardiovascular system, but may cause pulmonary irritations up to acute lung failure. (Simon 2008) 


\section{$2.3 \mathrm{H}_{2} \mathrm{~S}-90$ minutes of kidney ischemia}

With the knowledge of the previous $\mathrm{H}_{2} \mathrm{~S}$ experiment, we wanted to develop further the idea of a "suspended animation-like" status and its benefits to kidneys suffering from an ischemia and reperfusion sequence, especially since sulfide showed beneficially effects in renal I/R injury (Tripatara 2009, Xu 2009). These effects were also seen in porcine models dealing with myocardial $\mathrm{I} / \mathrm{R}$ injury and in isolated kidney preparations, mainly by the reduction of inflammatory response and oxidative stress (Sodha 2009, Hosgood 2010). Therefore we were interested if $\mathrm{H}_{2} \mathrm{~S}$ could reduce the renal tissue damage in our large animal model, described above with a special interest in the global kidney function, the animal metabolism, body temperature and parameters of inflammation and oxidative stress. After the initial bolus was given, the infusion rate was again $2 \mathrm{mg} / \mathrm{kg}$ per $\mathrm{h}$ for the first two hours but then was halved to $1 \mathrm{mg} / \mathrm{kg}$ per h. During the 90 minutes of aortic clamping the infusion rate was only $0.5 \mathrm{mg} / \mathrm{kg}$ per $\mathrm{h}$, to avoid toxic accumulation. For the rest of the procedure please see above. As already described, it is important to keep animals in comparable conditions to avoid artefacts. Hemodynamics, gas exchange, acid-base and electrolyte parameters did not differ between the two groups prior to aortic occlusion, except for a little difference in blood pressure level in the sulfide group that was a little bit lower compared to the control group. Again $\mathrm{H}_{2} \mathrm{~S}$ caused a fall of body temperature and heart rate and reduced again the need for noradrenaline. Postischemic acidosis and hyperkalemia were attenuated by sulfide. While there were comparable renal perfusion conditions the kidney function differed in favour for the $\mathrm{H}_{2} \mathrm{~S}$ animals. Plasma creatinine and creatinine clearance showed an improved function of the renal tissue while there was no difference in the fractional $\mathrm{Na}^{+}$-excretion. At the first glance it looks as if sulfide would not benefit renal tubular cells, but there is evidence, that it influences $\mathrm{Na}^{+}$-exchange directly, because $\mathrm{H}_{2} \mathrm{~S}$ caused a 5 fold increase in fractional excretion while there was only a rise of 50 to $80 \%$ in glomerular filtration (Xia 2009). Control animals showed "renal failure" and a "stage 2 kidney injury" in the RIFLE and AKIN classification (Cruz 2009). Sulfide caused only a mild increase of IL-6, IL-1 $\beta$ and nitrite + nitrate what came hand in hand with lower oxidative DNA base damage, measured with the comet assay, and iNOS expression, underlining the anti-inflammatory and NO-release attenuating effect of $\mathrm{H}_{2} \mathrm{~S}$ (Sodha 2009, Tripatara 2008, Hosgood 2010). The drop in body temperature is unlikely to be the reason as there is a deeper hypothermia recommended to affect inflammation in a relevant manner (Chen 2005). Heme oxygenase-1 (HO-1) and cleaved caspase-3 were similar in both groups while sulfide reduced expression of the anti-apoptotic protein Bcl-xL and increased nuclear transcription factor NF- $\mathrm{KB}$. Interestingly NF- $\mathrm{KB}$ not only has inflammatory properties, but also quite the opposite, especially in renal tissue and may contribute to the antiinflammatory effect seen in our experiment (Lawrence 2005, Panzer 2009). Contrary to the missing anti-inflammatory effect of the lower body temperature, there might be a beneficial effect of mild hypothermia on the protective properties of NF-אB during I/R injury (Kuboki 2007). The most important change in histopathology was the reduction of the "glomerular tubularization", while the rest of the histological staining only showed mild glomerular swelling, flattening of tubulus epithelium and intra-tubular deposits. Even TUNEL-staining showed comparable results between the two groups. This seems to be in contrast with other authors, evaluating more severe histological damages to the renal tissue after I/ $\mathrm{R}$ injury (Forman 2007, Sanchez-Conde 2008). 


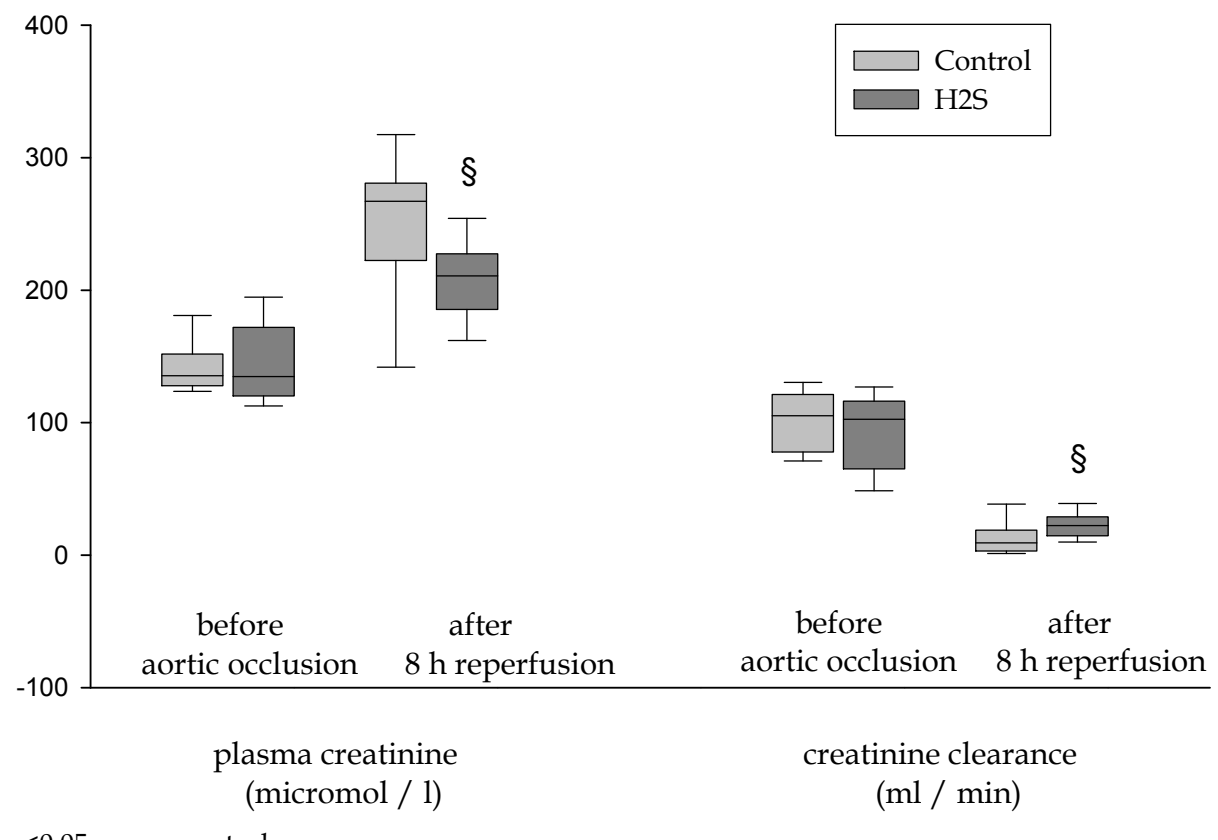

$\S \mathrm{p}<0.05$ versus control group.

Fig. 4. Blood creatinine levels and creatinine clearance in the control (light whiskers) and sulfide-treated animals (dark whiskers). All data are median (quartiles, range), control $n=10$, sulfide $n=9$,

The crucial point seems to be again the relatively short reperfusion period, because other experiments show comparable results after short post ischemic monitoring (Behrends 2000). This time factor seems also to be involved in the missing differences of HO-1 with a potential latency up to 24 hours (Calvert 2009). In conclusion we demonstrated in a clinically relevant porcine I/R injury model, that i.v. sulfide administration improved kidney function coming together with an anti-inflammatory effect and reduced DNA damage and NO release. The higher NF- $\mathrm{KB}$ activation was probably due to the drop in temperature (Simon 2011).

\section{Small animal model}

We established a small animal model to give answers to questions of the longer outcome of potential therapies, because in our pig model, with sacrifice of the animal at the end of the experiment the neurological outcome cannot be determined. The killing of the pigs at the end of the experiments is necessary, because of the positioning of the proximal balloon catheter, as described above, and the resultant hemodynamic imbalance as well as the ischemia of the abdominal organs. Much more compelling would be to monitor for several days the postoperative neurological outcome of awake animals after such an I/R injury. In New Zealand White Rabbit's spinal ischemia can be induced by cross-clamping of the 
infrarenal aorta due to strictly segmental blood supply of the spinal cord and can be therefore taken as a model for thoracic aortic clamping in pigs and humans respectively (Zivin 1980). In this way it is possible to keep the surgical impact relatively small, to avoid ischemia of the visceral organs and to keep hemodynamics stable without pharmacological intervention. Inspired by the experiments and experiences of our large animal model and the EPO drug (Simon 2008) we were interested now to examine the effects of a carbamylated derivative of EPO, the so called cEPO. Compared to EPO, whose neuroprotective abilities have been discussed above, the cEPO is lacking of the erythropoietic component (Doggrell 2004), but with all of the tissue protective characteristics of the native EPO. Cytoprotective effects are transmitted by a two-piece receptor, that has on the one hand an EPO receptor and on the other hand a special $\beta$-subunit. Experiments with mice lacking this subunit, showed no tissue protective effects (Brines 2004). This is of special interest, because erythropoiesis might be undesired in ill patients with hypertonia. 20 New Zealand White Rabbits were randomly distributed to either the control or the cEPO therapy group and were anesthetized by a mixture of ketamine $(50 \mathrm{mg} / \mathrm{kg}$ body weight) and xylazine $(5 \mathrm{mg} / \mathrm{kg})$. Blood pressure, heart rate, oxygen saturation and temperature were monitored intraoperatively. In preliminary trials a clamping time of $15 \mathrm{~min}$ was defined as being optimal. After this clamping time all animals imposed initially with complete paraplegia and a recovering during the first 24 hours with a following incomplete re-paraplegia as a sign of the reperfusion injury. Animals received vehicle or $\mathrm{cEPO}$ over a period of 30 minutes prior to ischemia and with the same doses during the first 30 minutes of reperfusion. Neurological tests took place at $6 \mathrm{~h}, 24 \mathrm{~h}$, $36 \mathrm{~h}, 48 \mathrm{~h}, 60 \mathrm{~h}, 72 \mathrm{~h}, 84 \mathrm{~h}$ and $96 \mathrm{~h}$ of reperfusion using a modified form of the Tarlov-score, describing the motoric-neurological function of the lower limbs, with a point score. After $96 \mathrm{~h}$ the spinal cord was taken out for histopathological examination.

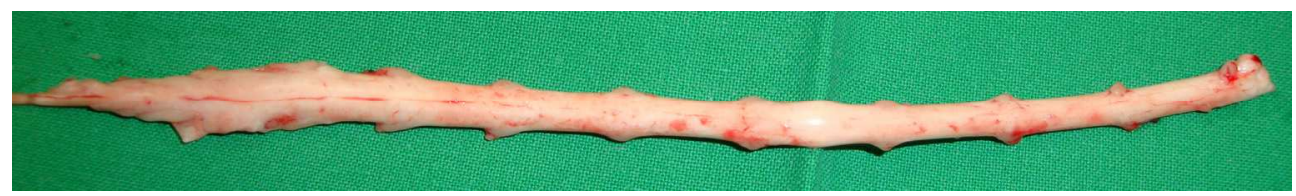

Fig. 5. Spinal cord explanted "in toto" after 96 hours of reperfusion (Th3-L5).

In the results the control and the therapy animals showed postoperatively complete paraplegia as supposed (Tarlov $=0$ ). After $6 \mathrm{~h}$ of reperfusion control animals recovered a little in the neurological examination (Tarlov $=4.25$ ). This improvement remained until $36 \mathrm{~h}$ of reperfusion with a subsequent deterioration until $96 \mathrm{~h}$ at the end of the experiment $($ Tarlov $=3.625)$. Aetiopathology in the $c E P O$ group was similar to the control group with a primary recovering up to $24 \mathrm{~h}$ after surgery (Tarlov $=4.25$ ) and a tableau until $36 \mathrm{~h}$ (Tarlov $=$ 4) and a subsequent worsening until $96 \mathrm{~h}$ (Tarlov = 3.5). There was unfortunately no significant difference between the two groups. Histopathological examination did not reveal any injury in thoracic sections of the spinal cord whereas damage in lumbal sections correlated significantly with neurological symptoms $(\mathrm{p}=0.007)$. The treatment group $(\mathrm{cEPO})$ and the placebo group showed no differences in neurological or histopathological outcome. Again we learned a lot out of this animal model especially that the time factor varies between different animal models. Even literature can not answer questions to the correct 
ischemia duration in a rabbit model, because some groups had good results after 15 minutes (Lee 2005) others needed 25 minutes (Jacobs 1992) or 30 minutes (Oz 2007) or even 40 minutes (Lafci 2008). We have to state that in our small animal model with rabbits a clamping time of 15 minutes may be questioned, because, as described above, we saw a fast recovering from paraplegia meanwhile the first 24 hours with no animal imposing with a complete paraplegia to the end after 96 hours.

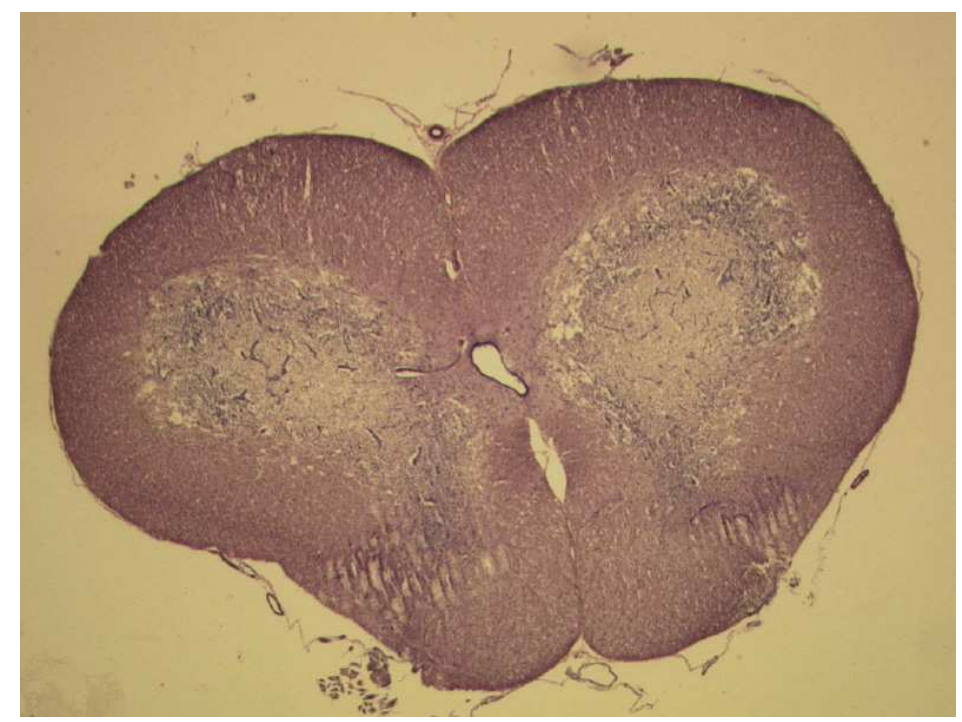

Fig. 6. Slice of the necrotic lumbar spinal cord (L2) with cellular inflammation reaction.

Our decision to work with a clamping time of 15 minutes is based on our aim to keep clamping time and surgery as short as possible to spare the animals. Looking now at the results we have to say that there is no difference between the groups and that we can not exclude the possibility that clamping time was too short. The neuronal damage was not big enough to see potential benefits of the treatment group, because the control group came out well, too. Therefore we can only speculate if the results are due to the short clamping time or just to the ineffectiveness of the cEPO drug. Statistically we found a huge range of variance in our results, what might be not unusual (Zivin 1980), but may disturb our database to see relevant intergroup differences. Therefore further investigations are warranted. In conclusion this is a highly reproducible model which allows clinical neurological assessment after aortic cross-clamping. Using this model promising pharmaceutics, influencing ischemia tolerance, can be tested clinically and histopathologically. In the initial experimental series with a cross-clamping time of 15 min no significant improvement of the clinical or histological damage could be achieved by administration of cEPO, what might be due to a too short clamping time (Simon 2010).

\section{Cell culture}

Cell culture is a possibility to illuminate processes on the level of genes and proteins as well as changings during hypoxia and reoxigenation. Additional substances and / or therapies 
can be tested before realising cost and time intensive large animal models. Subjects of interest are tubular and neuronal cells as representative tissue samples of the organs examined in our animal models described above. To realise this aim we used permanent human (HEK293) and porcine (LLC-PK1 and PK15) renal cells. Evaluation of the system was performed by determination of the hypoxia inducing factor 1 alpha (HIF1a) which plays an important role of the $\mathrm{O}_{2}$ regulation in every cell (Ivan 2001, Jaakkola 2001, Bardos 2004). We also determined expression of Proteinkinase beta 1 (AMPK $\beta 1$ ), which is activated by an elevated AMP/ATP ratio due to cellular and environmental stress, such as heat shock, hypoxia and ischemia (Hardie 2004). In both, human (HEK293) und porcine (LLC-PK1) kidney cells we saw that cells are quite tolerant to short (1-2 h) and middle (4-8 h) hypoxic periods, but a distinct upregulation of protein expression occurs after 18 to 24 hours of cultivation under hypoxic conditions. After $24 \mathrm{~h}$ of hypoxia the cells where reoxygenised. For characterisation of the system examinations of the cell morphology, distribution of intact, apoptotic and necrotic cells as well as expression of multiple apoptotic relevant genes on protein level were done. Induction of hypoxia is performed by manipulation of the $\mathrm{O}_{2}$ content of the cultivating medium, induced by a devolatilization of the cultivation medium and by using a standardised hypoxic chamber which is flushed with nitrogen. In this way we were able to combine different hypoxic timepoints with diverse reoxygenation durations. After putting the hypoxia medium on the cells they were cultivated in a hypoxic chamber. We compared normoxic cells with hypoxic ones. Expressions of the normoxic cells were taken as baseline and compared to hypoxic and reoxygenised cells, each with or without treatment. Target genes were caspase 3 and cleaved caspase 3 as a marker for apoptosis, HIF-1a (Hypoxia induced factor) to evaluate hypoxia, Bcl-2 and $\mathrm{Bcl} 2 \mathrm{xL}$ as antiapoptotic markers as well as Bax, as a proapoptotic marker of mitochondrial apoptosis. By using these methods it is possible to see differences in the gene expression in cells cultivated during hypoxic and normoxic conditions and how these things change under the treatment with potentially protective substances. After 24 hours of hypoxia we basically found expression of pro-apoptotic stimuli like Bax or rather severely deranged ratio of Bax and Bcl-2. We have Cytochrome c release, which can lead to activation of caspase 9 that processes caspase 3 and initiates to the formation of the apoptosome. And we have distinct release of other apoptotic factors, e.g. "Second-mitochondria-derived activator of caspase" in short Smac/Diablo, which counteracts the effect of inhibitors of apoptosis. These data are a second validation for our hypoxia model, because the intrinsic pathway of apoptosis begins when injury occurs within the cell, such as e.g. DNA damage, hypoxia and depravation of survival factors. Western blot was used to detect gene expression on protein level. Therefore proteins are isolated out of the target cells and then were separated by size using the "sodium dodecylsulfate polyacrylamide" gel electrophoresis (SDS-Page) and blotted on a nitrocellulose membrane. After treatment with a specific antibody, amplifying the primary antibody by a second one, it can be detected if a protein is expressed or not, compared to a standard protein in defined volume. To identify morphologic changings in mitochondria, cells were stained with the MitoTrackerRed, a mitochondria specific fluorescent dye. MitoTrackerRed Dyes stain mitochondria in living cells and its accumulation in the cell depends on the membrane potential. This means that a loss of fluorescence is caused by a decreased mitochondrial activity. 

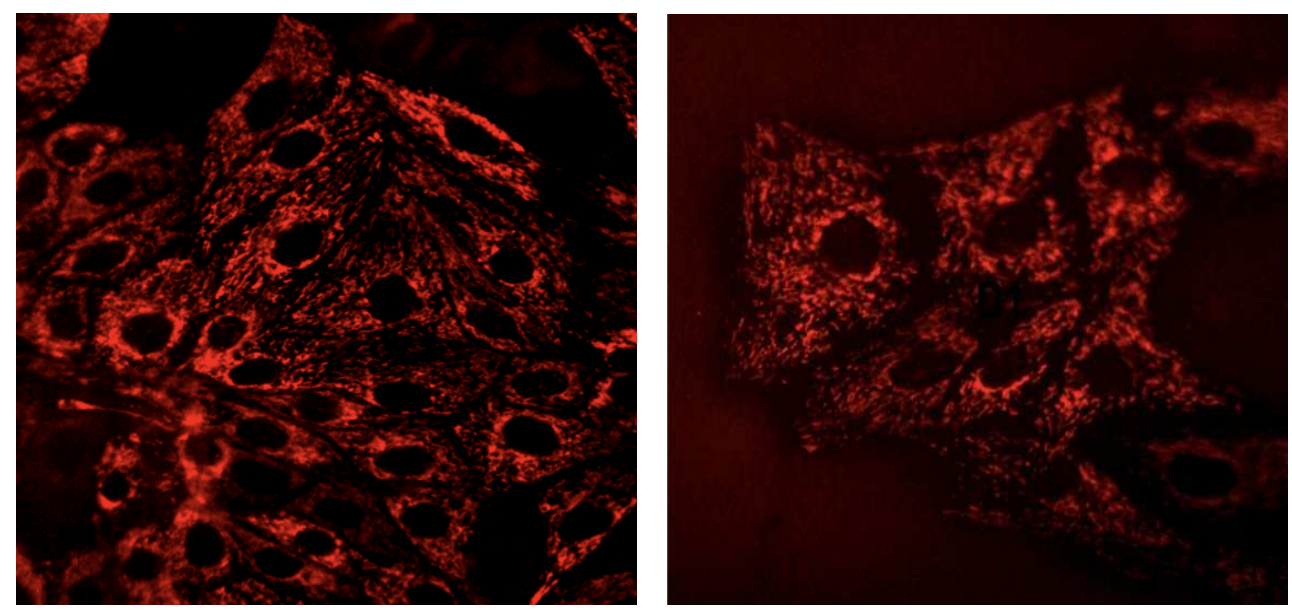

Fig. 7. MitoTrackerRed-staining in normoxic cells (left) and in cells after 24 hours of hypoxia (right).

We saw microscopic mitochondrial structures such as shape, localisation inside the cell and number of active mitochondria. Mitochondria seemed to be much more compact and after long terms of hypoxia, they partly seem to be more diffuse and also a loss of active mitochondria could be detected. Oxidative stress occurring during ischemia and reperfusion injury affects mitochondrial function and therefore respiratory chain. Thus, in addition, to follow changes in respiratory chain during hypoxic period and reoxygenation oxygraphical studies (Oxygraph, Oroboros; Austria) were performed. With that method by titration of inhibitors and substrates it is possible to follow changes in several complexes of the respiratory chain. Therefore it is possible to distinguish activities and dysfunction of the respiratory chain in particular. A classic titration protocol starts with state 1 respiration, which means endogenous substrates, no adenylates, with inorganic phosphates in the mitochondrial respiration medium. As expected we monitored a lowered state 1 respiration in hypoxic cells and a recovery after $24 \mathrm{~h}$ of reoxygenation. Another interesting point is the maximum respiration capacity of the cells and again, we found distinct lowered values in hypoxic cells and a slowly recovery after reoxygenation. We always compared normoxic cells with hypoxic ones. After these experiments we looked at the effects of EPO and cEPO on hypoxic cells. We tested two approaches. At first we admitted substances before the 24 hour hypoxic period and as second attempt during this period. What we saw is a downregulation of HIF-1a expression to nearly normoxic control level under high EPO / cEPO doses (100 - $1000 \mathrm{IU} / 5 \mathrm{ml}$ medium) given during hypoxia in human and pig kidney cells. Concerning activities on mitochondrial bases, we analysed $\mathrm{Bcl}-2$ as an anti-apoptotic mitochondrial marker and its antagonist Bax. We found a loss of Bcl-2 after 24 h hypoxic stress and a rise of Bax. So the Bcl-2/Bax ratio is severely deranged, which contributes to cellular apoptosis. But we also found these expressions re-adjusted with the help of EPO or cEPO. In addition we examined cellular proliferation, based on a luminescent assay. The assay, determining the number of viable cells in culture based on quantification of the ATP, is an indicator of metabolically active cells. The amount of ATP is directly proportional to the number of cells present in culture. What we saw, was no influence of cEPO in the control 
cells. As expected there was a reduced proliferation rate after $24 \mathrm{~h}$ of hypoxia, but also improved proliferation with cEPO treated cells. After $24 \mathrm{~h}$ of hypoxia and $24 \mathrm{~h}$ of reoxygenation nearly control level was reached again. In the long run we will work with primary renal and spinal cord cells, because I/R injury not only affect kidney but also spinal cord. Therefore we are interested in working with neuronal cells. Yet we did first steps with hippocampal primary neurons extracted from rat embryos, but in the near future it is planned not only to deprive oxygen but also to test a combination of oxygen and glucose deprivation. Also of particular importance is the examination of DNA damage during hypoxia, reoxygenation and drug treatment. Further projects will also deal with the effects of hypothermia on the cell system. The cell culture project is still developing and we learn a lot day by day so that these experiments, described above, are only the very beginning of our studies with cell culture and serves until now more or less only as a standardisation model with further projects and publications coming in the near future.

\section{Conclusion}

Aim of our studies is to examine systematically the phenomenon of the ischemia and reperfusion injury in common and in the aortic surgery in special. These experiments are important to develop pre- and perioperative concepts to improve clinical outcome of patients in the future. The models described above started their evolution 10 years ago and developed and expanded over the years. It is possible to study not only acute but also elective surgery situations and therefore might give answers to problems in the everyday life of a vascular surgeon to reduce morbidity and mortality in the aortic surgery.

\section{Acknowledgment}

The research of our group "Ischemia and reperfusion during aortic surgery" is kindly supported by the "Deutsche Gesellschaft für Gefäßchirurgie und Gefäßmedizin" and the "Deutsche Forschungsgemeinschaft".

\section{References}

Abdelrahman, M; Sharples, EJ; McDonald, MC et al (2004). Erythropoietin attenuates the tissue injury associated with hemorrhagic shock and myocardial ischemia. Shock 2004;22:63-69

Abe, A; Aoki, M (1995). Itoyama. Ischemic delayed neuronal death: a mitochondrial hypothesis. Stroke 26:1478-1489

Ates, E; Yalcin, AU; Yilmaz, S; Koken, T; Tokyol, C (2005). Protective effect of erythropoietin on renal ischemia and reperfusion injury. ANZ J Surg 2005;75:1100-1105

Back, MR; Bandyk, M; Bradner, M; Cuthbertson, D; Johnson, BL; Shames, ML; Bandyk, DF (2005). Critical analysis of outcome determinants affecting repair of intact aneurysms involving the visceral aorta. Ann Vasc Surg. 2005;19:648-56

Bárdos, JI; Chau, NM; Ashcroft, M (2004). Growth factor-mediated induction of HDM2 positively regulates hypoxia-inducible factor 1alpha expression. Mol Cell Biol. 2004;24(7):2905-14

Bhatia, M (2005). Hydrogen sulfide as a vasodilator. IUBMB Life 2005;57:603-606

Behrends, M; Walz, MK; Kribben, A; Neumann, T; Helmchen, U; Philipp, T; Schulz, R; Heusch, G (2000). No protection of the porcine kidney by ischaemic preconditioning. Exp Physiol 2000;85:819-827 
Bergner, R.; Porto, J.; Fedoronko, B. (1992). Selective deep hypothermia of the spinal cord prevents paraplegia after aortic crossclamping in the dog model. J Vasc Surg, 1992; 15: 62 - 72

Blackstone, E; Morrison, M; Roth, MB (2005). $\mathrm{H}_{2} \mathrm{~S}$ induces a suspended animation-like state in mice. Science 2005; 308:518

Blackstone, E; Roth, MB(2007). Suspended animation-like state protects mice from lethal hypoxia. Shock 2007;27:370-372

Blankensteijn, JD.; Lindenburg, FP.; Van der Graaf, Y.; Eikelboom, BC. (1998). Influence of study design on reported mortality and morbidity rates after abdominal aortic aneurysm repair. Br J Surg 1998; 85: 1624-30

Brines, M; Grasso, G; Fiordaliso, F et al (2004). Erythropoietin mediates tissue protection through an erythropoietin and common beta-subunit heteroceptor. Proc Natl Acad Sci USA 2004;101:14907-14912

Calvert, JW; Jha, S; Gundewar, S; Elrod, JW; Ramachandran, A; Pattillo, CB; Kevil, CG; Lefer, DJ (2009). Hydrogen sulfide mediates cardoprotection through Nrf2 signaling. Circ Res 2009; 105:365-374

Celik, M; Gokmen, N; Erbayraktar, S; et al (2002). Erythropoietin prevents motor neuron apoptosis and neurologic disability in experimental spinal cord ischemic injury. Proc Natl Acad Sci U S A 2002;99:2258-2263

Chen, Z; Chen, H; Rhee, P; Koustova, E; Ayuste, EC; Homma, K; Nadel, A; Alam, HB (2005). Induction of profound hypothermia modulates the immune/inflammatory response in a swine model of lethal hemorrhage. Resuscitation 2005;66:209-216

Couch, L; Martin, L; Rankin, N (2005). Near death episode after exposure to toxic gases from liquid manure. NZ Med J 2005;118:1-4

Crawford, E.; Svensson, L.; Hess, K.R. (1990). A prospective randomized study of cerebrospinal fluid drainage to prevent paraplegia after high-risk surgery on the thoraco-abdominal aorta. J Vasc Surg. 1990 13: 36 - 46

Cruz, DN; Ricci, Z; Ronoc, C (2009). Clinical review: RIFLE and AKIN - time for reappraisal. Crit Care 2009;13:211

Dodds, WJ (1982). The pig model for biomedical research. Fed Proc 1982; 41: 247-56

Doggrell, SA (2004). A neuroprotective derivative of erythropoietin that is not erythropoietic. Expert Opin Investig Drugs 2004;13:1517-1519

Ehrenreich, H; Hasselblatt, M; Dembowski, C et al (2002). Erythropoietin therapy for acute stroke is both safe and beneficial. Mol Med 2002;8:495-505

Fiorucci, S; Distrutti, E; Cirino, G; Wallace, JL (2006). The emerging roles of hydrogen sulphide in the gastrointestinal tract and liver. Gastroenterology 2006;131:250-271

Forman, CJ; Johnson, DW; Nicol, DL (2007). Erythropoietin administration protects against functional impairment and cell death after ischaemic renal injury in pigs. BJU Int 2007;99:162-65

Gelman, S (1995). The pathophysiology of aortic cross-clamping and unclamping. Anesthesiology 82(4):1026-1060

de Haan, P; Kalkman, CJ; Meylarts, SAG; Lips, J; Jacobs, MJHM (1999). Development of spinal cord ischemia after clamping of noncritical segmental arteries in the pig. Ann Thorac Surg 1999; 68: 1278-84

Hardie DG (2004). The AMP-activated protein kinase pathway - new players upstream and downstream. J Cell Sci 2004;117: 5479-5487 
Hatori, N; Yoshizu, H; Shimizu, M; Hinokiyama, K; Takeshima, S; Kimura, T; Iizuka, Y; Tanaka, S (2000). Prognostic factors in the surgical treatment of ruptured abdominal aortic aneurysms. Surg-Today.2000; 30(9): 785-90

Hellberg, A; Koga, I; Christiansson, L; Stiernstrom, H; Wiklund, L; Bergquist, D; Karacagil, S (2000). Influence of segmental spinal cord perfusion on intrathecal oxygen tension during experimental thoracic aortic crossclamping. J Vasc Surg 2000; 31: 164-170

Hosgood, SA; Nicholson, ML (2010). Hydrogen sulphide ameliorates ischaemia-reperfusion injury in an experimental model of non-heart-beating donor kidney transplantation. Br J Surg 2009;97:202-209

Ivan, M; Kondo, K; Yang, H; Kim, W; Valiando, J; Ohh, M; Salic, A; Asara, JM; Lane, WS; Kaelin, WG Jr. (2001). HIFa targeted for VHL-mediated destruction by proline hydroxylation: implications for O2 sensing. Science 2001;292: 464-468

Jaakkola, P; Mole, DR; Tian, YM; Wilson, MI; Gielbert, J; Gaskell, SJ; Kriegsheim, Av; Hebestreit, HF; Mukherji, M; Schofield, CJ; Maxwell, PH; Pugh, CW; Ratcliffe, PJ (2001). Targeting of HIF-1a to the von Hippel-Lindau ubiquitylation complex by O2regulated prolyl hydroxylation. Science 2001;292: 468-472

Jacobs, TP; Kempski, O; Mc Kinley, D et al (1992). Blood flow and vascular permeability during motor dysfunction in a rabbit model of spinal cord ischemia. Stroke 1992;23:267-373

Johansen, D; Ytrehus, K; Baxter, GF (2006). Exogenous hydrogen sulfide $\left(\mathrm{H}_{2} \mathrm{~S}\right)$ protects against regional myocardial ischemia/reperfusion injury. Evidence for a role of $K_{A T P}$ channels. Basic Res Cardiol 2006;10:53-60

Khan, AA; Schuler, MM; Prior, MG; Yong, S; Coppock, RW; Florence, LZ; Lillie, LE (1990). Hydrogen sulfide exposure on lung mitochondrial respiratory chain enzymes in the rat. Toxicol Appl Pharmacol 1990;103:482-490

Kaptanoglu, E; Solaroglu, I; Okutan, O; Surucu, HS; Akbiyik, F; Beskonakli, E (2004). Erythropoietin exerts neuroprotection after acute spinal cord injury in rats: effect on lipid peroxidation and early ultrastructural findings. Neurosurg Rev 2004;27:113-120

Kazautchian, PO. Protection of Kidney's from ischemic injuries through surgeries of aneurysms of thoracoabdominal and abdominal location. In: Thoracic and Thoracoabdominal Aortic Aneurysms: 177 - 187 Hrsg.: Weimann S. Monduzzi Edition, Bologna (1994)

Kick, J; Hauser, B; Bracht, H; Albicini, M; Öter, S; Simon, F; Ehrmann, U; Garrel, C; Sträter, J; Brückner, UB; Leverve, XM; Schelzig, H; Speit, G; Radermacher, P; Muth, CM (2007). Effects of a Cantaloupe melon extract/wheat gliadin biopolymer during aortic crossclamping.Intensive Care Med. 2007 Apr;33(4):694-702

Kuboki, S; Okaya, T; Schuster, R; Blanchard, J; Denenberg, A; Wong, HR; Lentsch, AB (2007). Hepatocyte NF- $\mathrm{KB}$ activation is hepatoprotective during ischemia-reperfusion injury asn is augmented by ischemic hypothermia. Am J Physiol Gastrointest Liver Physiol 2007;292:G201-G207

Lafci, B; Yasa, H; Ilhan, G et al (2008). Protection of the spinal cord from ischemia: comparative effects of levosimendan and iloprost. Eur Surg Res 2008;41(1):1-7

Lawrence, T; Bebien, M; Liu, GY; Nizet, V; Karin, M (2005). IKK $\alpha$ limits macrophage NF- $\kappa B$ activation and contributes to the resolution of inflammation. Nature 2005;434:1138-1142

Lee, J-C; Hwang, IK et al (2005). Histochemical and electron microscopic study of motoneuron degeneration following transient spinal cord ischaemia at normothermic conditions in rabbits. Anat Histol Embryol 2005; 34:252-257 
Łowicka, E; Bełtowski, J (2007). Hydrogen sulfide $\left(\mathrm{H}_{2} \mathrm{~S}\right)$ - the third gas of interest for pharmacologists. Pharmacol Res 2007;59:4-24

Meylaerts, SA; De-Haan, P; Kalkman, CJ; Lips, J (1999). The influence of regional spinal cord hypothermia on transcranial myogenic motor-evoked potential monitoring and the efficacy of spinal cord ischemia detection. J-Thorac-Cardiovasc-Surg.1999 Dec; 118(6): 1038-45

Meylaerts, SA; De-Haan, P; Kalkman, CJ; Jaspers, J; Vanicky, I; Jacobs, MJ (2000). Prevention of paraplegia in pigs by selective segmental artery perfusion during aortic cross-clamping. J-Vasc-Surg. 2000 Jul; 32(1): 160-70

Money, SR; Hollier, LH (1994). The management of thoracoabdominal aneurysms. Adv-Surg. 1994; 27: 285-94

Moon, C; Krawczyk, M; Paik, D; Lakatta, EG; Talan, MI (2005). Cardioprotection by recombinant human erythropoietin following acute experimental myocardial infarction: dose response and therapeutic window. Cardiovasc Drugs Ther 2005;19:243-250

Orend, KH.; Liewald, F.; Kirchdorfer, B.; Sunder-Plassmann, L. (1995). Management of descending aortic dissection. Ann Ital Chir. 1995; 66: 821-4

Oz Oyar, E; Korkmaz, A (2008). Aortic cross-clamping-induced spinal cord oxidative stress in rabbits: the role of a novel antioxidant adrenomedullin. J Surg Res 2007;147(1):143- 147

Panzer, U; Steinmetz, OM; Turner, JE; Meyer-Schwesinger, C; von Ruffer, C; Meyer, TN; Zahner, G; Gómez-Guerrero, C; Schmid, RM; Helmchen, U; Moeckel, GW; Wolf, G; Stahl, RA; Thaiss, F (2009). Resolution of renal inflammation: a new role for NF- $\mathrm{KB} 1$ (p50) in inflammatory kidney diseases. Am J Physiol Renal Physiol 2009;297:F429-F439

Roques, X; Remes, J; Laborde, M-N; Guibaud, J-P; Rosato, F; MacBride, T; Baudet, E (2003). Surgery of chronic traumatic aneurysm of the aortic isthmus: benefit of direct suture. EurJ-Cardiothorac-Surg.2003 Jan; 23(1): 46-9

Sakurai, M; Hayashi, T; Abe, K; Tabayashi, K (1998). DElayed selective motor neuron death and Fas antigen induction after spinal cord ischemia in rabbits. Brain Res 1998, 797(1):23-28

Sánchez-Conde, P; Rodríguez-López, JM; Nicolás, JL; Lozano, FS; García-Criado, FJ; Cascajo, C; Gonzáleeez-Sarmiento, R; Muriel, C (2008). The comparative abilities of propofol and sevoflurane to modulate inflammation and oxidative stress in the kidney after aortic crossclamping. Anesth Analg 2008;106:371-378

Schelzig, H; Sunder-Plassmann, L; Träger, K; Georgieff, M; Radermacher, P; Fröba, G (2003). Ischämie and Reperfusion des intestinalen und hepatischen Stromgebiets bei thorakalem crossclamping. Gefäßchirurgie 2003; 8: 92-99

Silver, M; Corvin, MJ; Bazan, A; Gettinger, A; Enny, C; Corwin, HL (2006). Efficacy of recombinant human erythropoietin in critically ill patients admitted to a long-term acute care facility: a randomized, double-blind, placebo-controlled trial. Crit Care Med 2006;34:2310-2316

Simon, F; Scheuerle, A; Calzia, E; Bassi, G; Oter, S; Duy, CN; Kick, J; Brückner, UB; Radermacher, P; Schelzig, H (2008). Erythropoietin during porcine aortic balloon occlusion-induced ischemia/reperfusion injury. Crit Care Med. 2008 Jul;36(7):2143-50

Simon, F; Giudici, R; Duy, CN; Schelzig, H; Öter, S; Gröger, M; Wachter, U; Vogt, J; Speit, G; Szabó, C; Radermacher, P; Calzia, E (2008). Hemodynamic and metabolic effects of hydrogen sulfide during porcine ischemia/reperfusion injury. Shock. 2008;30(4):359-64

Simon, F; Thiere, M; Erhart, P; Orend, KH; Schelzig, H; Oberhuber, A (2010). Präklinisches Kleintiermodell zur Erforschung von Ischämie- und Reperfusionsschäden des Rückenmarks nach Crossclamping der Aorta. Gefässchirurgie 2010;15(6): 463-7 
Simon, F; Scheuerle, A; Gröger, M; McCook, O; Stahl, B; Wachter, U; Vogt, J; Speit, G; Hauser, B; Möller, P; Calzia, E; Szabó, C; Schelzig, H; Georgieff, M; Radermacher, P; Wagner, F (2011). Effects of intravenous sulphide during porcine aortic occlusioninduced kidney ischemia/reperfusion injury. Shock 2011;35(2): 156-163

Sodha, NR; Clements, RT; Feng, J; Liu, Y; Bianchi, C; Horvath, EM; Szabó, C; Stahl, GL; Sellke, FW(2009). Hydrogen sulfide therapy attenuates the inflammatory response in a porcine model of myocardial ischemia/reperfusion injury. J Thorac Cardiovasc Surg 2009;138:977-984

Svensson, L.G.; Crawford, E.S.; Hess, K.R.; Coselli, J.S.; Safi, H.J. (1993). Experience with 1509 patients undergoing thoracoabdominal aortic operations. J Vasc Surg 1993; 17: 357 - 370

Tripatara, P; Patel, NS; Brancaleone, V; Renshaw, D; Rocha, J; Sepodes, B; Mota-Filipe, H; Perretti, M; Thiemermann, C (2009). Characterisation of cystathionine gammalyase/hydrogen sulphide pathway in ischaemia/reperfusion injury of the mouse kidney: an in vivo study. Eur J Pharmacol 2009;606:205-209

Truong, DH; Eghbal, MA; Hindmarsh, W; Roth, SH; O'Brien, PJ (2006). Molecular mechanisms of hydrogen sulfide toxicity. Drug Metabol Rev 2006; 38:733-744

Walther, A.; Bardenheuer, H-J. (2000). The abdominal aortic aneurysm. Anesthesiologic considerations and perioperative management in conservative surgical treatment. Anaesthesist. 2000 Jul; 49(7): 690-703

Wahlberg, E; Dimuzio, P-J; Stoney, R-J (2002). Aortic clamping during elective operations for infrarenal disease: The influence of clamping time on renal function. J-Vasc-Surg.2002 Jul; 36(1): 13-8

Willett, WC; Stampfer, MJ (2001). Clinical practice. What vitamins should I be taking, doctor? N Engl J Med 345(25):1819-1824

Xia, M; Chen, L; Muh, RW; Li, PL; Li, N (2009). Production and actions of hydrogen sulfide, a novel gaseous bioactive substance, in the kidneys. J Pharmacol Exp Ther 2009;329:10561062

$\mathrm{Xu}, \mathrm{Z}$; Prathapasinghe, G; Wu, N; Hwang, SY; Siow, YL; O, (2009). Ischemia-reperfusion reduces cystathionine-beta-synthase-mediated hydrogen sulfide generation in the kidney. Am J Physiol Renal Physiol 2009;297:F27-F35

Zhu, YZ; Wang, ZJ; Ho, P; Loke, YY; Zhu, YC; Hunag, SH; Tan, CS; Whiteman, M; Lu, J; Moore, PK (2007). Hydrogen sulfide and its cardioprotective effects in myocardial ischemia in experimental rats. J Appl Physiol 2007;102:261-268

Zivin, JA; DeGirolami, U (1980). Spinal cord infarction: a highly reproducible stroke model. Stroke 11(2):200-202

Zvara, D (2002). Thoracoabdominal aneurysm surgery and thr risk of paraplegia. J Extra Corpor Technol. 2002 Mar; 34(1):11-7 


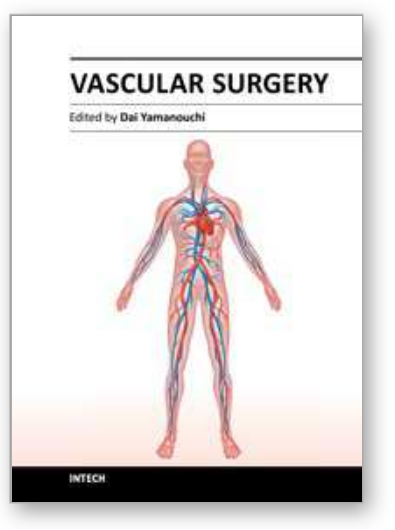

\author{
Vascular Surgery \\ Edited by Dr. Dai Yamanouchi
}

ISBN 978-953-51-0328-8

Hard cover, 262 pages

Publisher InTech

Published online 04, April, 2012

Published in print edition April, 2012

This book aims to provide a brief overview of conventional open vascular surgery, endovascular surgery and pre- and post-operative management of vascular patients. The collections of contributions from outstanding vascular surgeons and scientists from around the world present detailed and precious information about the important topics of the current vascular surgery practice and research. I hope this book will be used worldwide by young vascular surgeons and medical students enhancing their knowledge and stimulating the advancement of this field.

\title{
How to reference
}

In order to correctly reference this scholarly work, feel free to copy and paste the following:

Simon Florian (2012). How to Find New Ways, Vascular Surgery, Dr. Dai Yamanouchi (Ed.), ISBN: 978-95351-0328-8, InTech, Available from: http://www.intechopen.com/books/vascular-surgery/how-to-find-new-ways

\section{INTECH}

open science | open minds

\author{
InTech Europe \\ University Campus STeP Ri \\ Slavka Krautzeka 83/A \\ 51000 Rijeka, Croatia \\ Phone: +385 (51) 770447 \\ Fax: +385 (51) 686166 \\ www.intechopen.com
}

\author{
InTech China \\ Unit 405, Office Block, Hotel Equatorial Shanghai \\ No.65, Yan An Road (West), Shanghai, 200040, China \\ 中国上海市延安西路65号上海国际贵都大饭店办公楼 405 单元 \\ Phone: +86-21-62489820 \\ Fax: +86-21-62489821
}


(C) 2012 The Author(s). Licensee IntechOpen. This is an open access article distributed under the terms of the Creative Commons Attribution 3.0 License, which permits unrestricted use, distribution, and reproduction in any medium, provided the original work is properly cited. 